\title{
An Integral System Based on Open Organization of Agents for Improving the Labour Inclusion of Disabled People
}

\author{
Alejandro Sánchez, Carolina Zato, Gabriel Villarrubia-González, Javier Bajo, \\ and Juan Francisco De Paz \\ Departamento Informática y Automática, Universidad de Salamanca \\ Plaza de la Merced s/n, 37008, Salamanca, Spain \\ \{sanchezyu, carol_zato,gvg, jbajope,fcofds\}@usal.es
}

\begin{abstract}
This paper presents a system composed by a set of tools that facilitate the work of disabled people in their work environment. The PANGEA platform was used to build the base architecture of the system, where each tool is designed as a collection of intelligent agents that offer the services as Web-services. Moreover, all the system is implemented as an Open MAS. In this paper two tools are presented in detail, the proximity detection tool and the translator tool for people with hearing impairments.
\end{abstract}

Keywords: personalization workplace, disabled people, open MAS, agent platform, Zigbee, proximity detection, localization.

\section{Introduction}

Modern societies are characterized by two trends. The first is the rapid development of technologies, which has influenced our lives in many different ways. The second is the effort among governments, companies and associations toward enabling people with disabilities to have an independent life, which includes the possibility for remunerative employment. The effective integration of people with disabilities in the workplace is a huge challenge to society, and it presents an opportunity to make use of new technologies.

This paper presents a collection of tools that are being developed to formed an integral intelligent system. The different tools for the disabled people have been modelled with intelligent agents that use Web services. These agents are implemented and deployed within the PANGEA platform so they form an integral system that can be used regardless of their physical location or implementation. This project aims to develop new technologies that contribute to the employment of groups of people with visual, hearing or motor disabilities in office environments. Some of these tools are a head mouse to control the mouse with the eyes, a vibrator bracelet to send Morse messages, an avatar for the hearing impaired, a location system, etc. But due to space limitation, in this paper just an avatar and a proximity detection tool are presented. 
The rest of the paper is structured as follows: The next section introduces the basis of open MAS and the PANGEA platform. Section 3 presents the proximity prototype tool. Section 4 explains the translator tool. Next, section 5 presents a case study. Finally, in section 6 some conclusions are presented.

\section{Open MAS}

Open MAS can be understood as the following step in multi-agent systems. These are systems in which the structure is able to change dynamically. Its components are not known a priori, change over time and may be heterogeneous. The open MAS must allow the participation of heterogeneous agents with different architectures and even languages [18]. This makes it difficult to rely on the agents' behavior, and necessitates controls based on societal norms or rules. The proposed system has been designed as an open MAS.

Nowadays, there are many multi-agent systems which help and facilitate the work with the agents $[1,8,5]$. The only inconvenience of these systems is that they are for general purpose. The architecture that will be used in this paper must be able to assume the tasks for the integration of the persons with disabilities to the workplace. In this line, the most known works are:

- The European project CommonWell [2] proposes an architecture to support European citizens with limited mobility, or a hearing or visual impairment. However, it focuses on the elderly and does not incorporate either advanced adaptive interfaces or identification and localization elements.

- The European project DTV4A11 [3] proposes the use of digital television to integrate persons with disabilities, but it relies on the television as the only mechanisms to provide services.

- The European project MonAMI [15] proposes a global framework to offer services to the elderly and handicapped, but it focuses on providing these individuals with a more independent lifestyle.

At a Spanish national level we can find:

- The DISCATEL project [4] aims to incorporate persons with disabilities to Contact Centers or allow them to telecommute from their home or residence.

- The INREDIS project (Interfaces for the Relationship between people with Disabilities) [11] is a CENIT project headed by Technosite, which is investigating the concept of using personal devices with interoperability and ubiquitous characteristics to strengthen accessibility of persons with disabilities..

- The eVia platform has the INCLUTEC [10] study group, which is oriented toward analysis, and promotes the use and development of mobility mechanisms, such as assisted wheelchairs and specialized vehicle, alternative and enhanced communication, manipulation, and cognition.

None of this multiagent platforms shown previously, adapt to our requirements because most of them focus on the elderly or on the social integration of people with disabilities, instead of our goal, which is the labor inclusion of this kind of 
people. PANGEA architecture whose novelty is a dynamic and adaptable architecture capable of integrating new services for incorporating persons with visual, hearing, or mobile impairments into the workforce.

\subsection{Description of PANGEA}

PANGEA [20] is a service oriented platform that allows the implemented open MAS to take maximum advantage of the distribution of resources. To this end, all services are implemented as Web Services. Due to its service orientation, different tools modeled with agents that consume Web services can be integrated and operated from the platform, regardless of their physical location or implementation. This makes it possible for the platform to include both a service provider agent and a consumer agent, thus emulating a client-server architecture. The provider agent (a general agent that provides a service) knows how to contact the web service, while the remaining agents know how to contact with the provider agent due to their communication with the ServiceAgent, which contains information about services.

Once the client agent's request has been received, the provider agent extracts the required parameters and establishes contact. Once received, the results are sent to the client agent. Using Web Services also allows the platform to introduce the SOA (Service-oriented Architecture) [12] into MAS systems. SOA is an architectural style for building applications that use services available in a network such as the web. It promotes loose coupling between software components so that they can be reused. Applications in SOA are built based on services.

\section{Proximity Detection Tool}

The proximity detection system is based on the detection of presence using the ZigBee Technology [19]. Every computer in the room must have a Zigbee router assigned, and the system have to know their exact positions at every moment. Furthermore, all the users have to carry a Zigbee tag (Figure 1), which is responsible for the identifying each of them. Once the Zigbee tag carried by the person has been detected and identified, its location is delimited within the proximity of the sensor that identified it.

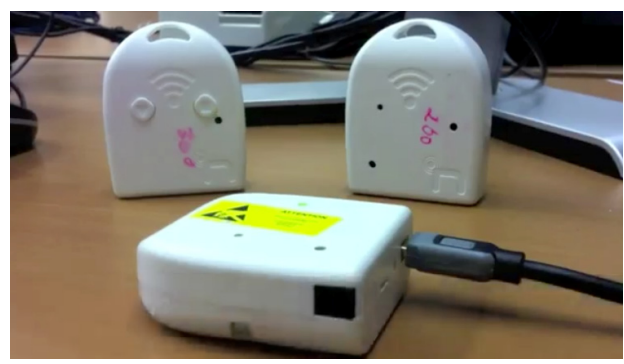

Fig. 1 Zigbee tags 
The agents that composed the tool are deployed in a specialized suborganization inside PANGEA, each one of these agents offer services (like a localization service) modeled as Web Services. The platform agents are implemented with Java, while the agents of the detection prototype are implemented in .NET and nesC.

Every user in the proposed system carries a Zigbee tag, which is detected by a ZigBeeReaderAgent located in each system terminal and continuously in communication with the ClientComputerAgent. Thus, when a user tag is sufficiently close to a specific terminal (within a range defined according to the strength of the signal), the ZigBeeReaderAgent can detect the user tag and immediately send a message to the ClientComputerAgent. The parameter RSSI is the responsible of measuring the receiving signal strength. The values fluctuate from an initial 0 to negative values. If values are close 0 , the user tag is near a computer. If the user moves away the workplace, values begin to be negatives. For switching on the computers, the Wake-on-LAN protocol is used due to the system uses a LAN infrastructure [16] [13].

Next, this agent communicates the tag identification to the UsersProfileAgent, which consults the database to create the xml file that is returned to the ClientComputerAgent. The ClientComputerAgent then interacts with the ServiceAgent to invoke the Web Services needed to personalize the computer according to the user's profile.

In Figure 2 the interface of the tool is shown. In the upper part, the main controller has options to manage computers, events, sensors and users. And below, the information about the identification once the ClientComputerAgent has finished the communication process with the UsersProfileAgent.

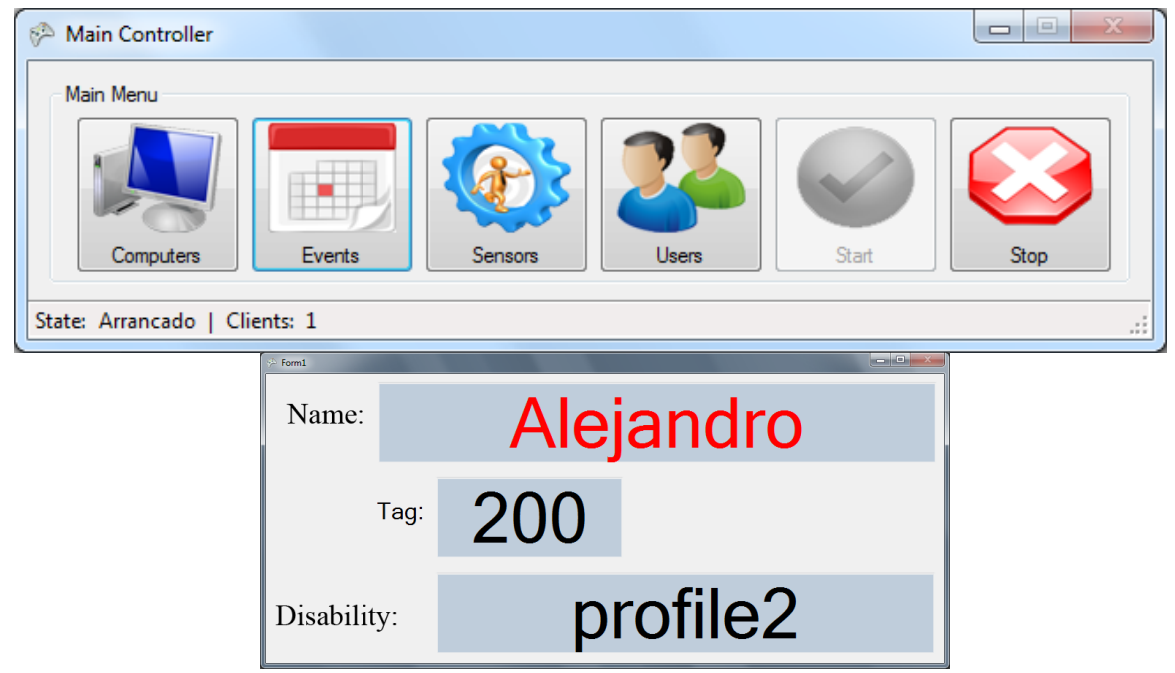

Fig. 2 Interface of the system 


\section{Translator Tool}

This tool emerged as a result of the difficulty encountered by employers in communicating to their hearing impaired employees the actions that they have to do in their jobs. Given the ineffectiveness of avatar translators, the solution chosen was to study the main communication needs and provide some recorded videos with commands and explanations specifically related to the performance of a particular job.

Once the computer has been switched on and personalized thanks to the proximity detection tool, the worker with a hearing impairment will see automatically the avatar on his screen. As can be seen in the figure 3, the avatar appears on the screen to indicate to the user the tasks that must be performed on this workday. The boss can send the tasks through email or text message, and the worker will receive them on the computer screen.

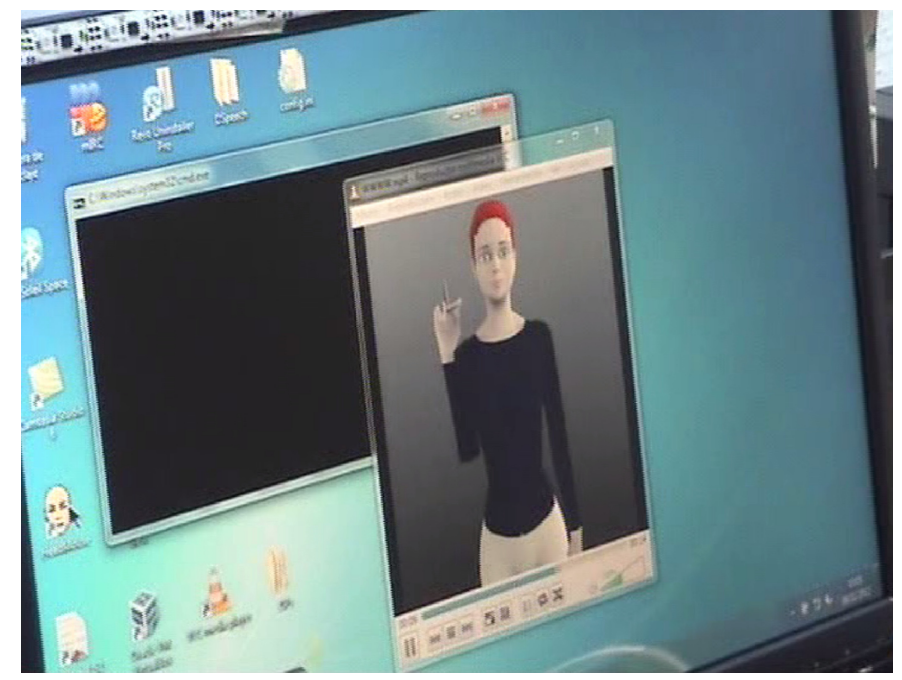

Fig. 3 Avatar of the translator tool

The issuing agents, deployed on both Smartphones (Android or iPhone) or computers, will be responsible for playing the video required at each moment. Receptor agents, also available for Smartphones or computers, will be responsible for capturing by text or by voice, the command or instruction that the employer wishes to transmit to the disabled employee.

In PANGEA, the translator agent is called VideoTranslatorAgent and it is deployed within the suborganization TranslatorOrganization. VideoTranslatorAgent is responsible for receiving the instruction and mapping the specific video used by the emitter agent who is requesting the transfer. The figure 4 shows all the agents involved in the functioning of the tool. 


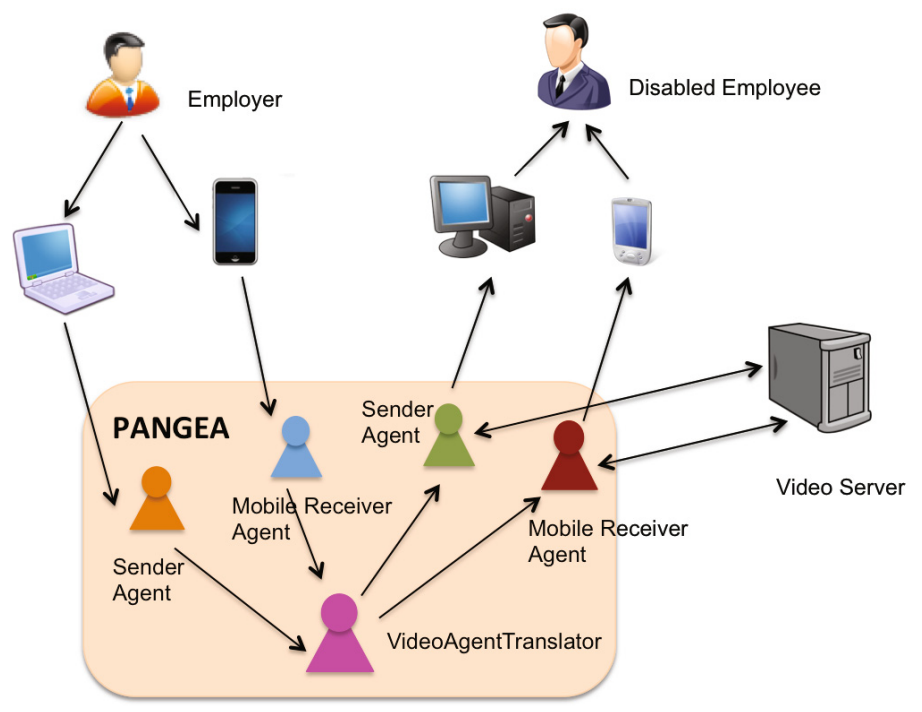

Fig. 4 Agents of the translator tool deployed in PANGEA

\section{Case Study}

All the tests have been centered on the final user. Tests have been carried out with individuals with different disabilities and a user profile exists for each person. User profiles stored data related to applications that are useful to users. These data can be classified according to the application, as shown in the following table.

Table 1 Data stored to personalize the computer

\begin{tabular}{|l|l|l|}
\hline \multicolumn{2}{|c|}{ Screen } \\
\hline Parameter & Value & Description \\
\hline usage & $1 / 0$ & $\begin{array}{l}\text { Field to describe if } \\
\text { this tool is used. }\end{array}$ \\
\hline invertColourChoice & $\begin{array}{l}\text { Field to describe if } \\
\text { the colors are } \\
\text { inverted. }\end{array}$ \\
\hline magnification & $1-200$ & $\begin{array}{l}\text { Field to describe the } \\
\text { level of magnification } \\
\text { the user want on the } \\
\text { screen. }\end{array}$ \\
\hline Parameter & Value & Avatar \\
\hline usage & Preferred/unpreferred & $\begin{array}{l}\text { Description to describe if this } \\
\text { tool is used. }\end{array}$ \\
\hline velocity & $1-10$ & $\begin{array}{l}\text { Field to describe the } \\
\text { speed of the signs. }\end{array}$ \\
\hline suze & $1-10$ & $\begin{array}{l}\text { Field to indicate the size } \\
\text { of the avatar }\end{array}$ \\
\hline localization & $1-10$ & $\begin{array}{l}\text { Field to where the avatar } \\
\text { is displayed on the } \\
\text { screen }\end{array}$ \\
\hline
\end{tabular}


Table 1 (continued)

\begin{tabular}{|l|l|l|}
\hline \multicolumn{3}{|c|}{ Language } \\
\hline Parameter & Value & Description \\
\hline lenguage & ISO 3166-1 alfa-3 & $\begin{array}{l}\text { Field to describe the user's } \\
\text { language }\end{array}$ \\
\hline \multicolumn{3}{|c|}{ Virtual Keyboard } \\
\hline Parameter & Value & Description \\
\hline usage & Preferred/unpreferred & $\begin{array}{l}\text { Field to describe if this } \\
\text { tool is used. }\end{array}$ \\
\hline \multicolumn{3}{|c|}{ Head Mouse } \\
\hline Parameter & Value & Description \\
\hline usage & Preferred/unpreferred & $\begin{array}{l}\text { Field to describe if } \\
\text { this tool is used. }\end{array}$ \\
\hline cursorAcceleration & $1-10$ & $\begin{array}{l}\text { Field to describe the } \\
\text { accelerating the } \\
\text { cursor. }\end{array}$ \\
\hline cursorSpeed & $1-10$ & $\begin{array}{l}\text { Field to describe the } \\
\text { speed of the cursor }\end{array}$ \\
\hline
\end{tabular}

The tests have helped us to fix the correct values and to refine the functioning of these tools.

\section{Conclusions}

This system is specifically oriented to facilitate the integration of people with disabilities into the workplace. Thanks of the PANGEA platform, the system can be easily designed and deployed since the platform itself provides agents and tools for the control and management of any kind of open MAS or VO. Moreover, the platform makes it possible to deploy different agents, even those included in the mobile devices, and communicates with the agents embedded in the Zigbee sensors. On the other hand, due to the based-on-services PANGEA implementation, the system has a high scalability and more tools can be added easily.

The presented system offers a multiagent system which is able to communicate with a proximity detection system and to personalize the workspace to improve the adaptation to the company flow. This individual adaptation allows that, whatever the disability the person has, the workplace will be adapted automatically, facilitating his productivity and removing the existing barriers, as the case of turning on the computer with the proximity detection system. Moreover, the translator tool will facilitate the communication in case the worker has hearing impairments.

Acknowledgements. This research has been supported by the project OVAMAH (TIN2009-13839-C03-03) funded by the Spanish Ministry of Science and Innovation.

\section{References}

1. Agent Oriented Software Pty Ltd., JACK ${ }^{\mathrm{TM}}$ Intelligent Agents Teams Manual. Agent Oriented Software Pty Ltd. (2005)

2. CommonWell Project (2010), http: / / commonwell .eu / index.php 
3. Digital Television for All project (2010), http: / /www . psp-dtv4all .org/

4. DISCATEL (2010), http: //www. imsersounifor.org/proyectodiscatel/

5. Galland, S.: JANUS: Another Yet General-Purpose Multiagent Platform. Seventh AOSE Technical Forum, Paris (2010)

6. Giunchiglia, F., Mylopoulos, J., Perini, A.: The tropos software development methodology: Processes, models and diagrams. In: Giunchiglia, F., Odell, J.J., Weiss, G. (eds.) AOSE 2002. LNCS, vol. 2585, pp. 162-173. Springer, Heidelberg (2003)

7. Huang, Y., Pang, A.: A Comprehensive Study of Low-power Operation in IEEE 802.15.4. In: Proceeding of the 10th ACM Symposium on Modeling, Analysis and Simulation of Wireless and Mobile Systems, Chaina, Crete Island, Greece (2007)

8. Hübner, J.F.: J -Moise+ Programming organisational agents with Moise+ \& Jason. Technical Fora Group at EUMAS 2007 (2007)

9. Ilyas, M., Dorf, R.C.: The handbook of ad hoc wireless networks. CRC Press Inc., Boca Raton (2003)

10. INCLUTEC (2011), http: / / www. idi.aetic.es/evia/es/inicio/ contenidos/documentacion/documentacion_grupos_de_trabajo/ contenido.aspx

11. INREDIS (2011), http: / /www. inredis.es /

12. Josuttis, N.M.: SOA in Practice. O’Reilly Media, Inc. (2007)

13. Lieberman, P.: Wake on LAN Technology, White paper (2011), http: //www. liebsoft.com/pdfs/Wake_On_LAN.pdf

14. Martin, D., et al.: OWL-S: Semantic Markup for Web Services, W3C Member Submission (2004), http: / / www .w3 . org/Submission/OWL-S /

15. Monami project (2010), http: / / www . monami . info/

16. Nedevschi, S., Chandrashekar, J., Liu, J., Nordman, B., Ratnasamy, S., Taft, N.: Skilled in the art of being idle: reducing energy waste in networked systems. In: Proceedings of the 6th USENIX Symposium on Networked Systems Design and Implementation, Boston, Massachusetts, pp. 381-394 (2009)

17. Razavi, R., Perrot, J.-F., Guelfi, N.: Adaptive modeling: An approach and a method for implementing adaptive agents. In: Ishida, T., Gasser, L., Nakashima, H. (eds.) MMAS 2005. LNCS (LNAI), vol. 3446, pp. 136-148. Springer, Heidelberg (2005)

18. Zambonelli, F., Jennings, N.R., Wooldridge, M.: Developing multiagent systems: The Gaia methodology. ACM Transactions on Software Engineering and Methodology 12(3), 317-370 (2003)

19. ZigBee Standards Organization: ZigBee Specification Document 053474r13. ZigBee Alliance (2006)

20. Zato, C., et al.: PANGEA - platform for automatic coNstruction of orGanizations of intElligent agents. In: Omatu, S., Paz Santana, J.F., González, S.R., Molina, J.M., Bernardos, A.M., Rodríguez, J.M.C. (eds.) Distributed Computing and Artificial Intelligence. AISC, vol. 151, pp. 229-240. Springer, Heidelberg (2012) 